\title{
PREVALENCE OF CHRONIC KIDNEY DISEASE IN PATIENTS WITH METABOLIC SYNDROME: A SINGLE CENTRE EXPERIENCE IN NIGERIA
}

\author{
Oghenekaro Godwin Egbi ( MPH, FMCP,FWACP)*, Evelyn Unuigbe**, Efosa Oviasu** \\ *Nephrology Unit, Department of Medicine, Niger Delta University, Okolobiri, Bayelsa State, Nigeria, \\ **Nephrology Unit, Department of Medicine, University of Benin Teaching Hospital, Benin City, Edo State, Nigeria.
}

\begin{abstract}
BACKGROUND

The prevalence of metabolic syndrome (MS) is increasing worldwide, not sparing developing countries like Nigeria. Chronic kidney disease (CKD) is also assuming epidemic proportions globally. Metabolic syndrome has been associated with CKD in several reports, most of which are foreign based. Given that data on CKD in MS patients is rare in this part of the world, the study was undertaken with the aim of determining the prevalence of CKD in patients with MS.
\end{abstract}

\section{METHODS}

Two hundred and twenty two subjects completed the study out of the two hundred and thirty that met the criteria for MS as defined by the harmonized criteria for definition of MS. CKD was defined as eGFR less than $60 \mathrm{ml} / \mathrm{min} / 1.73$ $\mathrm{m}^{2}$ as determined by the Modification of Diet for Renal Disease (MDRD) formula. Proteinuria was defined as presence of at least $1+$ of protein in urine in absence of leukocyturia or nitrituria.

\section{RESULTS}

Elevated blood pressure, elevated fasting glucose and central obesity were the commonest traits of MS. The prevalence of CKD in participants with MS was $20.3 \%$ while proteinuria was found in $121(54.5 \%)$ of them. The prevalence of CKD increased with additional traits of the syndrome.

\section{CONCLUSION}

CKD and proteinuria are prevalent in patients with metabolic syndrome. Prevalence of CKD in MS increases with additional component of the syndrome.

\section{KEY WORDS}

Blood pressure, cholesterol, diabetes, glucose, lipid, obesity

\section{INTRODUCTION}

The metabolic syndrome (MS) has evolved from a vague association of common chronic diseases to a formally defined cluster of clinical traits with adverse impact on cardiovascular risk. It may be characterized by abdominal

Corresponding Author: Oghenekaro Godwin Egbi, Nephrology Unit, Department of Medicine, Niger Delta University, PMB 100, Yenagoa,

Bayelsa State, Nigeria 
obesity, hyperglycaemia, hypertension, hypertryglyceridemia and reduced HDL cholesterol.

Several criteria have been put forward over time to aid in diagnosis of this condition. These include those by the World Health organization (WHO), ${ }^{1}$ European Group for the Study of Insulin resistance, ${ }^{2}$ the National Cholesterol Education Program Adult Treatment Panel (NCEP ATP) III, ${ }^{3}$ the American Association of Clinical Endocrinologists, ${ }^{4}$ the International Diabetes Federation(IDF) criteria. ${ }^{5}$ However in October 2009, a joint statement was issued by the International Diabetes Federation; National Heart, Lung, and Blood Institute; American Heart Association; World Heart Federation; International Atherosclerosis Society; and International Association for the Study of Obesity to standardize the diagnostic criteria for the metabolic syndrome. ${ }^{6}$ Agreed cut-points for all the components of metabolic syndrome were published and the diagnosis defined as the presence of any three or more abnormal findings: Elevated waist circumference(WC): population and country-specific; Serum triglycerides $(\mathrm{TG})>150 \mathrm{mg} / \mathrm{dl} /(1.7 \mathrm{mmol} / \mathrm{l})$ or drug treatment for elevated triglycerides; Serum HDL cholesterol $<40 \mathrm{mg} / \mathrm{dl}(1.0 \mathrm{mmol} / \mathrm{l})$ in men and $<50 \mathrm{mg} / \mathrm{dl}$ $(1.3 \mathrm{mmol} / \mathrm{l})$ in women or drug treatment for low HDL-C; Blood pressure $>130 / 85 \mathrm{mmHg}$ or drug treatment for elevated blood pressure(BP) and Fasting plasma glucose (FPG) $>100 \mathrm{mg} / \mathrm{dl}(5.6 \mathrm{mmol} / \mathrm{l})$ or drug treatment for elevated blood glucose.

About a quarter of the world population is estimated to suffer from metabolic syndrome. ${ }^{7}$ Its prevalence in developing countries has been observed to be on the increase lately and this may be related to changes in lifestyle and diet. ${ }^{89}$ Although it is widely known that the metabolic syndrome is a major risk factor for the development of cardiovascular disease and type 2 diabetes, evidence linking MS with CKD has also emerged. ${ }^{10,11}$ CKD has become a major public health problem, with a growing burden and significant impact on morbidity, mortality, quality of life, use of health services and health expenditure.

Mechanism by which the metabolic syndrome initiates or accelerates renal disease remains unclear but there are postulations that it may be related to the presence of obesity itself. Obesity has been shown to be an independent risk factor for CKD and has been associated with a type of focal segmental glomerulosclerosis called 'obesity-related glomerulopathy. ${ }^{12}$ Insulin resistance may have a direct role in the pathogenesis of renal injury, as a consequence of stimulating the sympathetic nervous system and reninangiotensin system. ${ }^{13}$ Dyslipidaemia, a feature of the metabolic syndrome may induce toxic and inflammatory tubulo-interstitial injury. ${ }^{14}$ Treating end stage renal disease (ESRD) imposes a large economic burden on the patients, the health care delivery system and the society at large. Considering the magnitude of the morbidity, mortality and huge cost of management of CKD and ESRD patients, it becomes imperative to adopt preventive strategies. Subjects with MS are thus candidates for CKD screening.
Studies on prevalence of CKD in metabolic syndrome patients are rare in developing countries like Nigeria. The aim of the study was to determine the prevalence of CKD in patients with metabolic syndrome in Benin City, Nigeria.

\section{METHODS}

The study was carried out in the University of Benin Teaching Hospital (UBTH), a tertiary health care centre in Benin City. Benin City is an ancient city and a cosmopolitan town located in Edo State in the South-Southern geopolitical zone of Nigeria. UBTH is a 600 bedded hospital and runs specialist hypertensive and diabetic clinics amongst other specialized services.

Consecutive hypertensive and diabetic patients attending the medical outpatient clinic of UBTH from September 2010 to May 2011 were screened for features of MS as defined by the harmonized criteria for definition of MS. ${ }^{6}$

A WC cut off of $94 \mathrm{~cm}$ for males and $80 \mathrm{~cm}$ for females was used according to the current recommended threshold for abdominal obesity in Sub-Saharan Africa. ${ }^{6}$

Patients that had at least three of the MS traits were recruited for the study. However, patients less than 18 years old, patients with CKD from other causes, apart from hypertension and diabetes, pregnant women, HIV patients and other wasting diseases, as well as patients with obvious ascites were excluded. Those with urinary tract infection as evidenced by leukocyturia or presence of nitrites in urine were also excluded from the study.

The sample size was determined using the formula, $\mathrm{N}=\mathrm{Z}^{2} \mathrm{pq} / \mathrm{d} .^{215}$

Where $\mathrm{N}=$ minimum sample size, $\mathrm{Z}=$ normal standard deviate at $95 \%$ confidence Interval $=1.96, \mathrm{P}=$ prevalence, $\mathrm{q}=1-\mathrm{p}, \mathrm{d}=$ precision set at 0.05

In a study of a group of Nigerians with metabolic syndrome by Ulasi et al, the overall prevalence of metabolic syndrome was $15.9 \%{ }^{16}$

Applying this as " $p$ " in the Fischer's formula, $N=\mathrm{Z}^{2} \mathrm{pq} / \mathrm{d}^{2}$ gives 205 .

However, to make allowances for drop-outs, 230 patients with MS were enrolled.

Using interviewer - administered questionnaire, sociodemographic data such as age, sex, marital status and ethnicity were obtained.

Blood pressure was taken using the Accoson mercury sphygmomanometer. For uniformity of measurement, the first sound (Korotkoff 1) was taken as the systolic blood pressure and the extinction of all sounds (Korotkoff 5) as the diastolic blood pressure. Blood pressure was recorded to the nearest $2 \mathrm{mmHg}$. Elevated blood pressure as a 
component of MS was defined as BP of $130 / 85 \mathrm{mmHg}$ or use of anti-hypertensives. ${ }^{[6]}$

Waist circumference (WC) was measured at a level midway between the lower rib margin and the iliac crest with the tape around the body in a horizontal position at the end of gentle expiration. Abdominal obesity was defined as waist circumferences of $>80 \mathrm{~cm}$ and $>94 \mathrm{~cm}$ for females and males respectively. ${ }^{6}$

Mid-stream urine was collected and analyzed for proteinuria with a combi 9 dipstix. For the purpose of this study, proteinuria was considered positive in the presence of at least $1+$ of protein in the absence of leukocyturia or nitrituria. Six mls of venous blood were collected from the participants and used for analysis of urea and creatinine and serum lipid profile after an overnight fast. The abbreviated version of the Modification of Diet in Renal Disease (MDRD) equation ${ }^{17}$ was used in estimating the glomerular filtration rate (GFR) viz: $\mathrm{eGFR}=186.3 \mathrm{x}$ (serum creatinine) $\exp [-1.154]$ age exp [0.203] x [0.724 if female] $x$ (1.21 if African). CKD was defined as eGFR $<60 \mathrm{mls} / \mathrm{min} / 1.73 \mathrm{~m}^{2}$

An HDL-C value of less than $50 \mathrm{mg} / \mathrm{dl}(1.3 \mathrm{mmol} / \mathrm{l})$ for females and $40 \mathrm{mg} / \mathrm{dl}(1.0 \mathrm{mmol} / \mathrm{l})$ for males was considered a significant component of MS. $^{6}$ For serum triglycerides, significantly elevated values were those $>150 \mathrm{mg} / \mathrm{dl}^{6}{ }^{6}$ FPG was determined using the accucheck glucometer and values $>100 \mathrm{mg} / \mathrm{dl}$ considered elevated. ${ }^{6}$ Individuals who were already on medications for elevated blood glucose irrespective of their present blood glucose readings were also enlisted. ${ }^{6}$

\section{ETHICAL CONSIDERATION}

Ethical approval was obtained from the Ethics and Research Committee of UBTH before commencement of the study. After a thorough explanation of the details of the study, the history to be obtained from participants as well as procedures to be performed, informed consent was obtained from those that were willing to partake in the study.

\section{DATA ANALYSIS}

Data was entered, stored and analyzed using the Statistical Package for Social Sciences for windows software version 17.0 (SPSS Inc., Chicago, IL, USA). Continuous variables were presented as mean, standard deviation and range while categorical variables were presented as frequencies and percentages. Fisher's exact test was used in testing for significant differences between groups. Results were presented in tabular forms. Confidence interval was at the $95 \%$ limit and $\mathrm{p}$ values of $<0.05$ were accepted as being statistically significant.

\section{RESULTS}

A total of five hundred and thirty hypertensive and diabetic patients were screened for metabolic syndrome. Out of this, two hundred and thirty (43.4\%) met the criteria for diagnosis of the syndrome. One hundred and sixty two of those that met the criteria were females while sixty eight were males. There was no significant difference in the proportion of male and female subjects with MS $(p=0.572)$. However, eight patients did not have complete data. Two hundred and twenty two participants had complete data which were the ones used in analysis.

\section{Characteristics of participants}

Out of the 222 participants that completed the study, 64(28.8\%) were males while $158(71.2 \%)$ were females.

The mean age of the participants was $60.0+11.4$ years. Majority $(80.2 \%)$ of them were married. Bini $(54.5 \%)$ was the dominant tribe. The socio-demographic data of the participants are shown in table1.

Two hundred and three (91.4\%) patients were either known hypertensives or had $\mathrm{BP}>130 / 85$ on presentation. One hundred and ninety $(85.6 \%)$ patients were either known diabetic patients or had an FPG $>100 \mathrm{mg} / \mathrm{dl}(5.6 \mathrm{mmol} / \mathrm{l})$. One hundred and seventy two $(77.5 \%)$ participants had abdominal obesity. Ninety four $(42.3 \%)$ participants either had TG $>50 \mathrm{mg} / \mathrm{dl}(\mathrm{mmol} / \mathrm{l})$ or were already on drug treatment for high TG while $117(52.7 \%$ ) participants had low HDL or were on drug treatment for low HDL. Participants had various combinations of these components ranging from three to all five.

\section{Prevalence of CKD}

The overall prevalence of CKD in the study was $20.3 \%$. The prevalence of CKD in patients with 3, 4 and 5 MS traits were $15.3 \%, 27.0 \%$ and $40.0 \%$ respectively showing an increasing prevalence with an increasing number of traits. This difference was observed to be statistically significant $(\mathrm{P}$ $=0.02$ ) as reported in table 2 .

Positive dipstick proteinuria was found in 121 (54.5\%) of the participants.

\section{DISCUSSION}

Most of the patients in this study were of Edo State Origin (Bini and Esan). This is to be expected, considering that the hospital is located in Edo state.

Among the five diagnostic traits for the metabolic syndrome, elevated blood pressure, hyperglycemia and abdominal obesity were the most prevalent in the patients. Similarly, these three traits were the most common components reported in Ervin's report among metabolic syndrome cohorts in the US though obesity had the highest frequency in that report. ${ }^{18}$ Hypertriglyceridemia and low HDL cholesterol were the least frequent traits among the metabolic syndrome patients. This is in agreement with documented reports of relatively low triglycerides and high HDL cholesterol 
conc entrations especially among Africans. ${ }^{19,} 20$ In Ulasi's series, hypertriglyceridemia was virtually non-existent in the patients. ${ }^{16}$

The prevalence of CKD in the MS patients in this series was $20.3 \%$. Unfortunately, there is a paucity of data on prevalence rates of $\mathrm{CKD}$ in $\mathrm{MS}$ patients to allow for adequate comparison with the findings from this study. However, Emem-Chioma et al reported low prevalence rates of $\mathrm{CKD}$ in $\mathrm{MS}$ patients of $4.8 \%$ in Rivers State, Nigeria, ${ }^{21}$ This is markedly lower than the findings of this study. Differing patient characteristics and methodology may have contributed to some of the observed differences. Their population was younger and the sample size was smaller. A Chinese study found a prevalence rate of $15.4 \%$ which is also less than the rate we found. ${ }^{22}$ Apart from possible ethnic and other demographic differences, the IDF criteria for MS was used in that study while we used the harmonized criteria.

Also, increased incidence rates of $\mathrm{CKD}$ with increased odds have been reported severally in prospective studies of patients with MS compared with the normal population ${ }^{10,23,24}$

There was a significant relationship between the number of components of MS and CKD. The prevalence of CKD was highest in those with all traits and least in those with only three components. Similar observations have been reported severally in literature. ${ }^{9,10,25}$ According to Lea of the Emory University, the individual components of the MS do not seem to have much effect on kidney disease progression but when taken together, the syndrome does seem to have a significant impact. ${ }^{26}$ There may thus be a synergistic effect among the various components in their association with CKD.

Over half of the patients had proteinuria. Although there was no control group for comparison, the prevalence of proteinuria in this study was indisputably high. Data in prevalence of proteinuria in metabolic syndrome is also rare. Jutilainen et al found a high prevalence of proteinuria in diabetic patients; $75.5 \%$ in men and $65.0 \%$ in women ${ }^{27}$ Another Central African study reported a prevalence of $23.8 \% .^{28}$ Even though only $5.7 \%$ of Korean subjects with the metabolic syndrome had proteinuria, proteinuria was still more in metabolic syndrome patients compared with $2.7 \%$ in patients without the syndrome..$^{29}$ This low rate is however not in agreement with our findings. The reason for this difference is not clear but differences in demographic characteristics may also be contributory.

It is therefore likely from our study that metabolic syndrome has a positive association with renal disease. The exact mechanism by which the metabolic syndrome initiates or causes progression of kidney disease remains unclear and is beyond the scope of the study but may however warrant further studies.

This study had some limitations. Serum creatinine assay was not repeated for the patients during the study. Since accurate diagnosis of CKD entails persistence of abnormalities for at least 3 months, there may have been some over-estimation in this regard. In addition, diagnosing hyperglycaemia using a finger-prick glucose meter has limitations. Blood glucose meters measure the glucose in whole blood which is actually lower than plasma glucose. Fortunately however, the glucometer used in this study gave results in plasma equivalent.

Also, this study was a hospital based one where the sample tested were patients who were already attending a specialist clinic. A population based study where the general population is screened would probably have been more apt. Also, the cohort in our study was voluntary and could have been biased by the health worker effect. A younger population may probably have been more appropriate since older patients are more likely to have other co-morbidities, which themselves, predispose to CKD. Since women made up a vast majority of the participants, there may be need for some caution in generalization of results.

Despite the above limitations, the findings of this study remain valid. The study has revealed a high prevalence of $\mathrm{CKD}$ in the metabolic syndrome which may be contributed to by a synergistic effect of all the components of the syndrome. There is therefore need for regular screening of patients with MS for CKD.

\section{REFERENCES}

1. World Health Organisation. Definition, diagnosis and classification of diabetes mellitus and its complications. Report of a WHO consultation 1999.

2. Balkau B, Charles MA. Comment on the provisional report from the WHO consultation. European Group for the Study of Insulin Resistance (EGIR). Diabet Med.1999;16:442-443.

3. Expert Panel on Detection, Evaluation, and Treatment of High Blood Cholesterol in Adults. Executive summary of the third report of the National Cholesterol Education Program (NCEP) expert panel on detection, evaluation, and treatment of high blood cholesterol in adults (Adult Treatment Panel III). JAMA. 2001;285:2486-2497.

4. Einhorn D, Reaven GM, Cobin RH, Ford E, Ganda $\mathrm{OP}$ et al. American College of Endocrinology position statement on the insulin resistance syndrome. Endocr Pract. 2003;9 : 237-252.

5. Alberti KG, Zimmet P, Shaw J. The metabolic syndrome-a new worldwide definition. Lancet.2005;366:1059-1062.

6. Dunstan DW, Zimmet PZ, Welborn TA, De Courten $\mathrm{MP}$, Cameron AJ et al. The rising prevalence of diabetes and impaired glucose tolerance. The Australian Diabetes, Obesity and Life Style Study. Diabetes care 2002; 28: 829-834.

7. Lutsey PL, Steffen LM, Stevens J. Dietary intake and the development of metabolic syndrome: the 
Atherosclerosis risk in communities study. Circulation 2008; 117:754-761.

8. Katzmaryk PT, Leon AS, Wilmore JH, Skinner JS, Rao DC et al. Targeting the metabolic syndrome with exercise. Evidence from the HERITAGE Family Study. Med Sci Sports Exerc 35(10):1703-1709.

9. Chen J, Muntner P, Hamm LL, Jones DW, Batuman $\mathrm{V}$ et al. The metabolic syndrome and chronic kidney disease in US Adults. Ann Intern Med 2004; 140 (3): $167-174$.

10. Kurella M, Lo JC, Chertow GM. Metabolic syndrome and the risk for chronic kidney disease among non diabetic adults. J Am Soc Nephrol 2005; 16:21342140.

11. Kambham N, Markowitz GS, Valerie AM, Lin J, D'Agati VD. Obesity related glomerulopathy: An emerging epidemic. Kidney Int 2001; 59:1498-1509.

12. Sowers JR. Insulin resistance and hypertension. Am J Physiol Heart Circ Physiol 2004; 286:H1597-H1602

13. Sun L, Halaihel N, Zhang W, Rogers T, Levi M. Role of sterol regulatory element- binding protein 1 in regulation of renal lipid metabolism and glomerulosclerosis in diabetes mellitus. J Biol Chem 2002; 277:19-27.

14. Alberti KGMM, Eckel RH, Grundy SM, Zimmet PZ, Cleeman JI et al. Harmonizing the Metabolic Syndrome. A Joint Interim Statement of the International Diabetes Federation Task Force on Epidemiology and Prevention; National Heart, Lung, and Blood Institute; American Heart Association; World HeartFederation; International Atherosclerosis Society; and International Association for the Study of Obesity. Circulation. 2009; 120: 1640-1645.

15. Daniel WW. Biostatistics: A foundation for analysis in the Health Sciences. 7th ed. New York: John Wiley and Sons Publishers, 1999.

16. Ulasi II, Ijoma CK, Onodugo OD. A communitybased study of hypertension and cardiometabolic syndrome in semi-urban and rural communities in Nigeria. BMC Health Serv Res 2010; 10:71.

17. Levey AS, Bosch JP, Lewis JP. A more accurate method to estimate glomerular filtration rate from serum creatinine: A new prediction equation. Modification of Diet in Renal Diseases Study Group. Ann Intern Med 1999; 130:461-470.

18. Ervin RB. Prevalence of metabolic syndrome among adults 20 years of age and over, by sex, age, race and ethnicity, and body mass index: United States, 20032006. Natl Health Stat Report 2009:1-7.

19. Glueck CJ, Gartside P, Laskarzewski, PM, Khoury P, Tyroler HA. High-density lipoprotein cholesterol in blacks and whites: potential ramifications for coronary heart disease. Am Heart J 1984;108: 815826.

20. Frerichs RR, Srinivasan SR, Webber LS, Berenson GR. Serum cholesterol and triglyceride levels in 3,446 children from a biracial community: the Bogalusa Heart Study. Circulation.1976; 54:302-309.

21. Emem-Chioma P C, Siminialayi I M, Wokoma F S. Prevalence of chronic kidney disease in adults with metabolic syndrome. Saudi J Kidney Dis Transpl 2011; 22:949-954.

22. Zhang L, Zuo L, Wang F, Wang M, Wang S et al. Metabolic syndrome and chronic kidney disease in a Chinese population aged 40 years and older. Mayo Clin Proc 2007; 82(7):822- 827.

23. Ryu S, Chang Y, Woo H, Lee K, Kim SG et al. Time dependent association between metabolic syndrome and risk of CKD in men without hypertension or diabetes mellitus. Am J Kidney Dis 2009; 53(1):5969.

24. Ninomiya T, Kiyohara Y, Kubo M, Yonemoto K, Tanizaki $\mathrm{Y}$ et al. Metabolic syndrome and CKD in a general Japanese population: the Hisayama study Am J Kidney Dis 2006; 48(3)383-391.

25. Tanaka H, Shiohira Y, Higa A, Iseki K. Metabolic syndrome and chronic kidney disease in Okinawa, Japan. Kidney Int 2006; 69:369-374.

26. Lea J, Cheek D, Thornley-Brown D. Metabolic Syndrome, proteinuria and the risk of progressive CKD in hypertensive, African Americans. Am J Kidney Dis 2008; 51(5):732-40.

27. Jutilainen S, Lehto S, Ronnemaa T, Pyorala K, Laakso M. Proteinuria and metabolic syndrome as predictors of cardiovascular death in non-diabetic and type 2 diabetic men and women. Diabetologia 2006; 49:5665 .

28. Rolfe M. Diabetic renal disease in Africa. Diabetic Medicine 1988; 5(7):630-633.

29. Myung-Ju O, Mi-J L, Kee-Hyuck L, Min-Seon P, Jeong AK. Association of proteinuria with metabolic syndrome in Korean Adults. Korean J Fam Med 2010; 31(6):437-443 
Tables

Table 1: Socio-demographic data of the MS patients

\begin{tabular}{|c|c|c|c|}
\hline Variable & $\begin{array}{l}\text { Mean } \pm \text { SD } \\
\text { (yrs) }\end{array}$ & $\begin{array}{l}\text { Range } \\
\text { (yrs) }\end{array}$ & $\begin{array}{l}\text { Frequency } \\
\text { n (\%) }\end{array}$ \\
\hline Age & $60.0 \pm 11.4$ & $29-91$ & \\
\hline \multicolumn{4}{|l|}{ Sex } \\
\hline Male & & & $64(28.8)$ \\
\hline Female & & & $158(71.2)$ \\
\hline Total & & & $222(100.0)$ \\
\hline \multicolumn{4}{|c|}{ Marital status } \\
\hline Single & & & $4(1.8)$ \\
\hline Married & & & $178(80.2)$ \\
\hline Widowed & & & $39(17.6)$ \\
\hline Separated & & & $1(0.4)$ \\
\hline Total & & & $222(100.0)$ \\
\hline \multicolumn{4}{|l|}{ Tribe } \\
\hline Bini & & & $121(54.5)$ \\
\hline Esan & & & $35(15.8)$ \\
\hline Delta Ibo & & & $19(8.6)$ \\
\hline Urhobo & & & $8(3.6)$ \\
\hline Etsako & & & $8(3.6)$ \\
\hline Ika & & & $6(2.7)$ \\
\hline Others & & & $25(11.2)$ \\
\hline Total & & & $222(100.0)$ \\
\hline
\end{tabular}


Table 2: Relationship between number of metabolic syndrome traits and CKD

Chronic kidney disease

\section{No of MS}

Traits

3

4

5

Total
Yes

$22(15.3 \%)$

$17(27.0 \%)$

$6(40.0 \%)$

$45(20.3 \%)$
No

$122(84.7 \%)$

$46(73.0 \%)$

$9(60.0 \%)$

$15(100.0 \%)$

Fisher's exact $\mathrm{p}=0.02$

\section{LIST OF ABBREVIATION}

$\begin{array}{ll}\text { ATP } & \text { Adult treatment panel } \\ \text { BP } & \text { Blood pressure } \\ \text { CKD } & \text { Chronic kidney disease } \\ \text { eGFR } & \text { Estimated glomerular filtration } \\ \text { ESRD } & \text { end stage renal disease } \\ \text { FPG } & \text { Fasting plasma glucose } \\ \text { HDL } & \text { High density lipoprotein } \\ \text { HDL-C } & \text { High density } \\ \text { HIV } & \text { Human immunodeficiency virus Lipoprotein cholesterol } \\ \text { HTN } & \text { Hypertension } \\ \text { LDL } & \text { Low density lipoprotein } \\ \text { LDL-C } & \text { Low density lipoprotein Cholesterol } \\ \text { MDRD } & \text { Modified diet in renal disease } \\ \text { MS } & \text { Metabolic syndrome } \\ \text { NCEP } & \text { National cholesterol education Program } \\ \text { TG } & \text { Triglyceride } \\ \text { UBTH } & \text { University of Benin Teaching Hospital } \\ \text { WC } & \text { Waist circumference }\end{array}$

